\title{
Economic Benefits of Energy Efficiency to the Petroleum Refineries in Ghana: A Case of Tema Oil Refinery (TOR)
}

\author{
David Ayo' $^{1}$, Jones Lewis Arthur ${ }^{1,2}$ (), Kwadwo Adinkrah-Appiah ${ }^{3}$ \\ ${ }^{1}$ Institute of Distance Learning, Kwame Nkrumah University of Science and Technology, Kumasi, Ghana \\ ${ }^{2}$ Faculty of Applied Science and Technology, Sunyani Technical University, Sunyani, Ghana \\ ${ }^{3}$ Faculty of Engineering, Sunyani Technical University, Sunyani, Ghana \\ Email: ayodavidm@gmail.com, jonesarthur2002@yahoo.co.uk, jonesarthur2002@stu.edu.gh, jojoappiah2001@yahoo.com
}

How to cite this paper: Ayo, D., Arthur, J.L. and Adinkrah-Appiah, K. (2021) Economic Benefits of Energy Efficiency to the Petroleum Refineries in Ghana: A Case of Tema Oil Refinery (TOR). Open Journal of Energy Efficiency, 10, 121-135. https://doi.org/10.4236/ojee.2021.104008

Received: September 22, 2021 Accepted: November 16, 2021 Published: November 19, 2021

Copyright $\odot 2021$ by author(s) and Scientific Research Publishing Inc. This work is licensed under the Creative Commons Attribution International License (CC BY 4.0).

http://creativecommons.org/licenses/by/4.0/

\begin{abstract}
This study investigates the economic benefits of energy efficiency to petroleum refineries regarding Tema Oil Refinery (TOR), Ghana. The study explores lessons relating to the cost of production, energy recovery levels and economic fortunes of the refinery activities and designs a conceptual framework for improving the energy efficiency of Tema Oil Refinery (TOR). The study adopted a descriptive design using a quantitative approach to provide a statistical background to investigate the economic benefits of energy efficiency. A sample of 84 was adopted for study from a staff population of 520 working at Tema Oil refinery. In addition to primary data, secondary data on energy supply and consumption values from 2008 to 2019 was gathered. For the primary survey, 84 respondents were sampled from TOR and a structured questionnaire was used to retrieve information. A correlation analysis at $\mathrm{P}<$ 0.05 was conducted to test the relationship and significance of energy efficiency and economic benefits to the refinery. The study concludes that there is a linear trend between energy production (supply) and energy consumption. The energy generated in the entire economy of Ghana far exceeds the amount of energy consumed thus raising issues of waste or excesses that calls for better policies and management plan to improve EE. The study also identified that issues of lost energy are critical to the operations of the petroleum industry as the situation is compounded by the inability of the refineries to explore better ways to reduce and manage the waste. The study concludes that a significant and positive correlation between energy efficiency and the economic fortunes of Tema Oil Refinery is necessary for its economic fortunes. The supply of energy should have equivalence to the public consumption of energy.
\end{abstract}




\section{Keywords}

Efficiency, Refinery, Petroleum, Economic Benefit, Recovery, Production Cost

\section{Introduction}

This study investigates the economic benefits of energy efficiency to petroleum refineries regarding Tema Oil Refinery (TOR), Ghana. The study explores lessons relating to the cost of production, energy recovery levels and economic fortunes of the refinery activities. The study finds out how increased energy efficiency can reduce the cost of production associated with the refinery activities as well as encourage economic buoyancy to provide an economically beneficial environment to the refinery.

Energy Efficiency (EE) emphasizes the goal to reduce the amount of energy required to provide products and services [1]. Energy efficiency also relates to the use of less energy to provide the same level of energy [2]. It is, therefore, one method to reduce the adverse impacts of the use of energy such as greenhouse gas emissions. Efficient energy use deals with a means to derive more efficient technology or process. But, the issue of energy efficiency has attracted much attention in recent literature due to the potential positive impacts it could have on reducing energy demand and usage.

[3] argues that the energy efficiency school of thought proposes end-use energy utilization for eight energy items by incorporating end-use vitality proficiency pointers as well as carbon force markers for four areas (private sector, administration, industry and transport). These pointers are processed by utilizing action data for key sectors of the economy. Some literature has quantified energy productivity to be unique and linked to many dimensions of energy efficiency [4]. For example, power level consumption changes across nations relying upon modes of transport (for example, street, air, water, rail), vehicle types (for example traveller vehicles, transports, and so on) and on the normal inhabitancy (travellers per vehicle) has diminished over time as individuals progressively drive their vehicles as single occupants [4]. On energy consumption in the assembling sectors, the normal assembling energy force in a nation is considered to rely upon the general load of the distinctive sub-parts in the assembling blend. For instance, the force is especially high in nations like Nigeria, where the paper and printing industry-which is vitality serious accounted for about $57 \%$ of absolute assembling energy utilization in 2017 [5]. Taking a gander at private structures, energy proficiency upgrades for space warming is followed by patterns in private space warming force characterized as vitality utilization per floor zone [3].

Improving energy proficiency, by diminishing the amount of devoured vitality, can upgrade the security of vitality. Vitality productivity implies utilizing less 
vitality to achieve a similar errand [6] [7]. More proficient utilization of vitality across a nation would reduce the expenditure burden on energy users such as property holders, schools, government offices, organizations and businesses. The cash that would have been expended could rather be spent on different things like training, buyer merchandise/items and other benefits. Energy conservation through improved effectiveness and preservation has potential impacts on accommodating the objectives of financial turn of events, energy security and natural assurance [8].

Energy effective pointers essentially have diminished in numerous IEA nations including The Netherlands, Portugal, Germany and Ireland who have encountered decreases of over $35 \%$ since 2000 [3]. Nations with warmer climates including Ghana by and large have lower space warming forces, as less vitality is required on normal, to keep the temperature inside private structures at comfortable levels.

Ensuring Energy efficiency has the end benefit of reducing the cost at which energy is sold to the final consumer as well as improving the longevity of its usage. However, [9] has reported that there have been several energy inefficiencies in the petroleum sector [9] [10]. The Commission further adds that Tema Oil Refinery loses a lot of energy in producing petroleum products such as gasoline and diesel. The inefficiencies in the energy system that also influence energy recovery levels are mainly blamed on the lack of capital, outdated technology and limited skilled persons on oil sites. The implications for energy inefficiencies in Ghana's economy are low revenue accruals as well as instability in employment in the sector.

Some literature has indicated that energy efficiency is an important component of a company's environmental strategy, including those in the petroleum industries [11] [12] [13]. Although the final points of sale of energy are often expensive and inefficient, energy efficiency can be the cheapest opportunity to reduce pollutant emissions and have high economic benefits for refineries [14]. However, it is important to note that oil refining is one of the biggest vitality expending parts of energy, devouring around 4 percent of all-out worldwide essential vitality utilization [15]. Ensuring energy efficiency at the refineries is an important but daunting task. For example, a fruitful, financially savvy speculation into vitality proficient innovations and practices would address the difficulty of keeping up the energy yield, decreased production cost and improve energy recovery levels [16]. Alternately, higher energy proficiency is frequently connected with higher profitability, vitality and creation advancement regularly connected, and vitality productivity costs lowered [17] [18].

Cost-effective investment is especially important, as energy-efficient technologies often include additional benefits, such as increasing the productivity of the company, reducing the marginal cost of production to a globally acceptable minimum and improving energy efficiency and or recovery levels. But these globally acceptable standards have barely being achieved in sustaining energy efficiency in Ghana. As mentioned, the lack of capital and outdated technology are 
the leading causes of this challenge. But a huge assortment of chances exists inside oil treatment facilities to decrease vitality utilization while keeping up or improving the efficiency of the plant. Studies by a few organizations in oil refining including Tema Oil Refinery (TOR) have exhibited the presence of a significant potential for vitality effectiveness improvement in practically all offices [16] [17].

Tema Oil Refinery (TOR) is the chief oil processing plant in Ghana. The processing plant was among the initial eight treatment facilities in Africa, as of 1963. The processing plant produces a 45,000 barrel for each stream day (bpsd) limit Crude Distillation Unit and supplies this amount out of the public interest of 65,000 bpsd [19]. Many experts argue that the efficiency of the refinery machinery is weak and as a result plays no direct economic benefit to the refinery and Ghana as a whole [11] [20]. Other experts have also argued that obtaining new refinery technology will improve efficiency as well as provide consistency and also reduce the current high cost of production.

According to [11], energy efficiency in the oil sector of Ghana has become very critical because of the minimal effort being made toward the achievement of higher efficiency. Without an efficient energy management practice, there will be no form of sustainable energy in Ghana's petroleum sector. [21] indicated that there are approved ways of ensuring energy efficiency in oil-producing countries-Ghana is however yet to fully ensure higher efficiency levels and improve sustainability. Ghana generates energy from hydropower, fossil fuel (thermal energy), and renewable energy sources. Energy generation is one of the key means to improving the development of Ghana's economy. The Energy Efficiency Policy Review, commissioned by the Energy Commission in 2015 under the China-Ghana South-South Cooperation and financed by the Danish government identified gaps and Solutions in Ghana's Report. The partnership identified gaps that impact energy efficiency in the petroleum sector and also found that fossil energy source is critical at the level of increasing energy consumption.

The 2010 Ghana National Energy Policy envelops cross-slicing intends to deal with the significant test of quickly developing vitality requirements for the public advancement plan. These underline the requirement for improved help strategy, and for the private sector inclusion to cultivate manageable and productive vitality age. As indicated by the [10], Ghana's sustainable power source advancement will fundamentally concentrate on the huge little hydro capability of the nation. Consequently, 21 small scale and medium-hydro power locales, with limits extending from $4 \mathrm{~kW}$ to $325 \mathrm{~kW}$, have just been recognized as reasonable for age. Ghana likewise has extraordinary potential for squandering to-vitality and biomass, essentially recovery of woody biomass assets, and the National Energy Policy puts more accentuation on biofuel age ventures. Sun-oriented radiation additionally gives generous potential to control age, and expanded government uphold for the public sun-based assembling segment which framed piece of public vitality strategy. Meanwhile, [3] indicates that the implementation of energy policies has barely made an impact in ensuring energy efficiency in Ghana's re- 
fineries. This assertion creates a bigger problem that ought to be investigated. Various policy directions have been recommended for the petroleum industry. These include the non-parametric data development analysis approach [22] achieving EE through reduced consumption [23] and application of new technology [10].

In addition, Ghana Energy Commission argues that issues of inadequate research and development, weak demonstration and deployment as well as poor financing of energy investments as key factors undermining energy efficiency in the sector. Currently, the crude furnace of Tema Oil Refinery (TOR) is producing at a very low capacity $(25,000 \mathrm{bpsd})$ but at a very high cost of production per barrel (over $\$ 30 \mathrm{bp}$ ). This raises a mandatory question regarding the economic benefits of the refinery amidst minimal production rates and faulty furnaces of the refinery. The concern of how energy efficiency can be improved for TOR to enjoy some economic benefits in terms of its cost of production. Therefore, this study assesses data on energy losses/gains as well as energy supply during the operational process of TOR. The study, therefore, examines the trends in Energy Efficiency (EE) in the Petroleum Sector of Ghana; assesses the energy recovery levels of Tema Oil Refinery (TOR); and examines the relationship between Energy Efficiency EE and the economic fortunes of Tema Oil Refinery (TOR).

\section{Methods}

The researcher used a quantitative (descriptive) approach of research to provide a statistical background to investigate the economic benefits of energy efficiency. These are the parts of the study that have informed the use of the quantitative approach. Furthermore, the descriptive design was also adopted to examine perceptions of the key variables being investigated. A descriptive study is useful in defining a subject by constructing the profile of people, groups or events through tabulation and the collection of data on study variables. An explanatory structure is utilized in this investigation. An illustrative structure likewise guarantees supreme clarification of the situation and ensures that there is no predisposition in information assortment, and empowers information assortment from a noteworthy objective populace or informational collection in a practical way. Therefore, an explanatory design helped to establish the economic benefits of energy efficiency with an examination of profitability and production levels of the Tema Oil Refinery.

[24] defines population as the total of items for which the information is desired. The population of the study is the staff of Tema Oil refinery made up of 520 current active staff of Tema Oil Refinery (TOR).

The size of the sample decides the factual exactness of the discoveries. As indicated by [25], when directing examination one can't consider everyone, all over the place, doing everything. As a rule, when directing quantitative exploration, one, as a rule, chooses an example of individuals, settled in their unique circumstances and concentrated inside and out. For sampling to be effectively 
done a handful of respondents who are ready to respond to the data instrument was sampled. An estimate of 84 respondents was, therefore, obtained. This sample size is obtained from the application of [26] formulae for establishing a sample size.

$$
n=\frac{N C^{2}}{C^{2}+(N-1) e^{2}}=\frac{520(0.5)^{2}}{0.5^{2}+(520-1)(0.05)^{2}}=84.00
$$

where $n$ is the sample size, $N$ is the population, $C$ is the coefficient of variation (0.5), $e$ is the level of precision (0.05) [26]. For a total staff of, a sample size of 84 was obtained for the study.

The procedure for sampling respondents of TOR to respond to the primary data instrument was based on probability sampling. The simple random sampling method was used to sample the staff of TOR who is in charge of the engineering section of the refinery. A simple random sampling technique will then be employed to select at least 84 staff across the 520 staff.

Secondary data from the latest annual published statements from the Tema Oil refinery was used in the study. The data on energy recovery levels were obtained for a period of 10 years from the year 2008 to 2017. Data from secondary data reports are considered reliable since they are prepared based on standardized accounting/economic/engineering principles. Primary data in the form of questionnaires will be used to solicit information from experts within the Tema Oil Refinery using well-structured questionnaires.

The research instrument used was the annual published statements from the Tema oil refinery for the period, 2008 to 2017. This instrument represents secondary data that helped with the analysis of the trends in energy efficiency and the recovery levels of the Tema Oil refinery. The primary data instrument in the form of a well-structured questionnaire was also used to elicit information from staff on the economic benefits of energy efficiency.

The questionnaire was divided into four sections where demographic information of staff will be accessed for section A. Section B inquired about issues regarding energy efficiency at TOR. Section D accessed staff energy recovery levels at TOR. The research questionnaire adapted [27] that explored the energy efficiency of oil refineries. The questionnaire used a 5 point Likert scale to measure/quantify responses. The five-point Likert scale included; $1=$ Strongly Disagree, 2 = Disagree, 3 = Neutral, $4=$ Agree, $5=$ Strongly Agree.

The questionnaire was administered using face to face approach and virtual means such as Google forms. The research instrument was administered to only technical and financial staff of Tema Oil refinery that are willing and ready to provide the necessary information needed for the completion of the research. Face to face method of administration as well as virtual methods of data gathering was used. Pre-testing was conducted amongst the staff of Tema Oil refinery to test the reliability and validity of the research questions.

Data was collected, edited, sorted for completeness and then analyzed using IBM Statistical Product and Service Solutions (SPSS) software version 23 to 
conduct inferential statistical analysis.

In the establishment of the objectives of the study variables such as profitability and production level of oil were used to assess the economic benefits of EE to TOR. Descriptive statistical analysis in the form of Means, Standard Deviations and Trends were used as well. At a 95\% confidence level, the $t$ and F-test were used in the determination of the statistical significance of this research. The significance of regression coefficients was tested by $\mathrm{t}$-test whereas the determination of the significance of regression equation was tested by F-test. Hence the Asymptotic or significance of the variables was valued at $\mathrm{P}<0.05$.

Reliability was assured by calculating Cronbach's alpha statistic to estimate reliability. [28] recommends 0.7 as the accepted benchmark for Cronbach's alpha. [28] argues that, if the coefficient alpha is too low, the indication is that the items measuring the scale have very little in common. Therefore, a Cronbach's alpha of at least 0.70 will be ensured.

The researcher assured ethical consideration by adhering to a permission note/letter on conducting a study at TOR with a positive response from TOR to allow this study to be conducted. The sampled respondents were given adequate time and space to fill the questionnaire.

\section{Results}

The first part of the results described the trends of energy supplied and consumed whereas the second part explored statistical tools such as mean and standard deviation. The inferential analysis used correlation statistics to examine the relationship between energy efficiency and energy fortunes. In sum, the following specific objectives were assessed; examined the trends in Energy Efficiency (EE) in the Petroleum Sector of Ghana, assessed the energy recovery levels of Tema Oil Refinery (TOR), examined the relationship between Energy Efficiency (EE) and economic fortunes of Tema Oil Refinery (TOR), and designed a conceptual framework for improving the energy efficiency of Tema Oil Refinery (TOR).

\subsection{Demographic Background of Respondents}

Of the 84 respondents, $69 \%$ are males while $31 \%$ are females. The presentation showed that males are more dominant than female respondents.

Out of 84 staff of Tema Oil Refinery, $45.3 \%$ (38) represent the 30 - 39 years age group, $27.4 \%$ (23) for 30 - 39 years and $19.0 \%$ (16) for 50 - 59 years. The least age group was 20 - 29 years with only $8.3 \%$ (7) respondents. In all, 60.7\% (51) respondents have attained Masters' level education while $39.3 \%$ (33) had a first degree. The dominant educational level amongst Staff of Tema Oil Refinery is the masters' level.

\subsection{Energy Supplied}

Energy efficiency is indicated by the difference between the energy produced and 
consumed. Since 2008, energy supplied has been a little above 6000 kilotonnes and later dipped in 2009. From 2010 to 2017 the amount of energy produced or supplied have steadily increased but later dipped in 2018. In 2019 however, the amount of energy supplied exceeded 8000 kilotonnes. Overall, there has been a gradual increase in the amount of energy supplied in the Ghanaian economy.

\subsection{Energy Consumed}

The consumption of energy increased from 5187 kilotonnes in 2008 to $7421 \mathrm{ki}-$ lotonnes in 2019. The yearly difference between energy consumed in 2008 to 2019 sums up to above 2000 kilotonnes. The consumption patterns have been marginally increasing. The total consumption in 2015 and 2016 was marginally higher than energy consumption in 2017. The lowest energy consumption was experienced in 2015 while the highest was experienced in 2019.

\subsection{Economic Benefits of Energy Efficiency in Tema Oil Refinery}

Table 1 presents descriptive statistics on the economic benefits of energy efficiency. On the issues of factors that improve the economic fortunes of Energy Efficiency (EE) for TOR, Higher performance is achieved when TOR is energy efficient ranked highest (mean $=4.22$, S.D. $=0.574)$ whilst There exist cost-effective energy efficiency measures that improve our operations was least ranked (mean $=3.27$, S.D. $=0.961$ ).

\subsection{Energy Efficiency of Tema Oil Refinery}

On mean raking for ensuring $\mathrm{EE}$ at TOR, the issue of Energy generation is monitored against consumption was ranked highest $($ Mean $=4.14$, S.D. $=0.541)$.

Table 1. Descriptive statistics of economic benefits of energy efficiency.

\begin{tabular}{|c|c|c|c|}
\hline Statements & $\mathrm{N}$ & Mean & Std. Deviation \\
\hline $\begin{array}{l}\text { Higher performance is achieved } \\
\text { when TOR is energy efficient }\end{array}$ & 84 & 4.33 & 0.574 \\
\hline $\begin{array}{l}\text { Monetary benefits have been } \\
\text { accrued out of the efficient use of energy }\end{array}$ & 84 & 4.12 & 0.547 \\
\hline $\begin{array}{l}\text { Efficient monitoring of energy } \\
\text { generation has ensured lasting plants }\end{array}$ & 84 & 4.04 & 0.768 \\
\hline $\begin{array}{l}\text { The estimated payback time for } \\
\text { investing in energy efficiency is relatively short }\end{array}$ & 84 & 3.49 & 0.925 \\
\hline $\begin{array}{l}\text { Energy is conserved with the } \\
\text { application of energy efficiency policy }\end{array}$ & 84 & 3.29 & 0.687 \\
\hline $\begin{array}{l}\text { There exist cost-effective energy } \\
\text { efficiency measures that improve our operations }\end{array}$ & 84 & 3.27 & 0.961 \\
\hline
\end{tabular}

Source: Field Survey, 2020 Mean Scale: $1.00-1.49=$ Strongly Disagree; $1.50-2.49=$ Disagree; $2.50-3.49=$ Neutral; $3.50-4.49=$ Agree; $4.50-5.00=$ Strongly Agree; $\mathrm{SD}<0.5=$ Closely spread data. 
The least ranked variable for EE was Energy performance is high at (mean = 0.44 , S.D. $=0.628$ ). There is a mix of responses regarding the Energy efficiency of Tema Oil Refinery. Generally, 3 out of the 6 indicators were ranked above men 3.5 showing the key roles those variables played in ensuring EE at TOR (Table 2).

\subsection{Energy Recovery Levels of Tema Oil Refinery}

The energy recovery levels are promising for TOR as the majority of the indicators for EE provide better energy recovery levels for the industry. Of the 6 indicators, 5 provided positive input to energy recovery levels of TOR. The highest-ranking variable was energy recovered in time is reusable in other parts of the refinery $($ mean $=4.23$, S.D. $=0.608)$ as against the lowest-ranked variable of There is accurate control of furnace temperature that makes it easy for recovery purposes $($ mean $=3.55$, S.D. $=0.501)($ Table 3$)$.

Table 2. Descriptive statistics of energy efficiency.

\begin{tabular}{|c|c|c|c|}
\hline Statement & $\mathrm{N}$ & Mean & Std. Deviation \\
\hline Energy generation is monitored against consumption & 84 & 4.14 & 0.541 \\
\hline $\begin{array}{c}\text { Machines used in generating energy often } \\
\text { undergo maintenance }\end{array}$ & 84 & 3.64 & 0.482 \\
\hline Efficient Energy is generally recorded with steam & 84 & 3.61 & 0.491 \\
\hline Consumption records are adjusted to energy price change & 84 & 2.95 & 0.727 \\
\hline Energy performance is high & 84 & 2.73 & 0.628 \\
\hline $\begin{array}{l}\text { The level of energy generation commensurate } \\
\text { to the output obtained }\end{array}$ & 84 & 2.44 & 0.499 \\
\hline
\end{tabular}

Source: Field Survey, 2020 Mean Scale: 1.00 - $1.49=$ Strongly Disagree; $1.50-2.49=$ Disagree; $2.50-3.49=$ Neutral; $3.50-4.49=$ Agree; $4.50-5.00=$ Strongly Agree; $\mathrm{SD}<0.5=$ Closely spread data.

Table 3. Descriptive statistics of energy recovery levels.

\begin{tabular}{|c|c|c|c|}
\hline Statement & $\mathrm{N}$ & Mean & Std. Deviation \\
\hline $\begin{array}{l}\text { Energy recovered in time is } \\
\text { reusable in other parts of the refinery }\end{array}$ & 84 & 4.23 & 0.608 \\
\hline There are periodic audits made on energy recovery levels & 84 & 3.88 & 0.589 \\
\hline Staff are aware of techniques used in energy recovery levels & 84 & 3.81 & 0.595 \\
\hline The energy lost from the plant cannot be recovered & 84 & 3.60 & 0.594 \\
\hline There is an explicit policy on energy recovery levels & 84 & 3.55 & 0.501 \\
\hline $\begin{array}{c}\text { There is accurate control of furnace temperature } \\
\text { that makes it easy for recovery purposes }\end{array}$ & 84 & 3.31 & 0.728 \\
\hline
\end{tabular}

Source: Field Survey, 2020 Mean Scale: $1.00-1.49=$ Strongly Disagree; $1.50-2.49=$ Disagree; $2.50-3.49=$ Neutral; $3.50-4.49=$ Agree; $4.50-5.00=$ Strongly Agree; $\mathrm{SD}<0.5=$ Closely spread data. 


\subsection{Inferential Analysis on the Relationship between Energy Efficiency and Energy Fortunes of Tema Oil Refinery}

The inferential analysis for EE of TOR is shown in Table 4. The Pearson correlation of 0.289 showed that the efficiency of energy produced has a weak positive correlation with the benefits or fortunes of energy. This further shows that issues of energy fortunes are explained by $28.9 \%$ EE. The significant value of 0.008 showed that Energy efficiency has a significant association with energy benefits or fortunes. Overall there is a significant and positive correlation between energy efficiency and the energy fortunes of Tema Oil refinery.

\section{Discussions}

This section discusses the findings of the study as related to EE and the energy fortunes of TOR.

\section{Trends in Energy Efficiency (EE) in the Petroleum Sector of Ghana}

The secondary data analysis presented a detailed graphical representation of trends using data gathered from National Energy statistics. The analysis showed that there is a linear trend between energy production (supply) and energy consumption. Energy production increases go with energy supply consumption as well. However, the amount of energy generated in the entire economy of Ghana far exceeds the amount of energy consumed thus raising concerns on issues of waste or excesses. The study results support [3] [4] that argued for effective energy productivity to improve EE. This further highlights the need to efficiently manage energy further because of out-match consumption levels. Some scholars have made similar assertions regarding the poor efficiency of Ghana's energy sector. According to [29], the management of energy in most West African nations is largely poor and has no sustainable plans to effect. The results are similar to [30] that indicated that energy produced in most developing nations is not efficiently managed following consumption rates and patterns but argued that efficiency programmes are largely absent in most countries. The study further corroborates [6] that argued that Energy efficiency is about using less energy to accomplish the same task. But, [29] posits that the management of energy in

Table 4. Correlations.

\begin{tabular}{cccc}
\hline Variables & Measured & Energy Fortunes & Energy Efficiency \\
\hline \multirow{2}{*}{ Energy Fortunes } & Pearson Correlation & 1 & $0.289^{* *}$ \\
& Sig. (2-tailed) & $\mathrm{N}$ & 0.008 \\
\hline \multirow{2}{*}{ Energy Efficiency } & Pearson Correlation & $0.289^{* *}$ & 84 \\
& Sig. (2-tailed) & 0.008 & 1 \\
& $\mathrm{~N}$ & 84 & 84 \\
\hline
\end{tabular}

${ }^{*}$ Correlation is significant at the 0.01 level (2-tailed). 
most West African nations is largely poor and that many of such states do not even have sustainable plans in place. This assertion further supports [30] that argued that energy consumption rates and patterns in most developing nations are poorly managed.

\subsection{Energy Recovery Levels of Tema Oil Refinery (TOR)}

The results of the study confirm that staff is aware of techniques used in ensuring energy recovery levels at the refinery and that periodic audits are made on energy recovery levels. Findings further showed that when energy is recovered in time it is reusable in other parts of the refinery. Overall there is a positive assertion regarding the energy recovery levels of Tema Oil Refinery and this affirms information from the literature [12] [13]. The results further confirm that even though governments over the years have had the provision of energy services high on the national development agenda, past and existing policies and plans have not delivered effective results to accelerate energy efficiency and recovery levels.

\subsection{Relationship between Energy Efficiency and Economic Fortunes of Tema Oil Refinery (TOR)}

The inferential statistics were used to determine the relationship between energy efficiency and the economic fortunes of Tema Oil Refinery. The inferential analysis confirmed a significant and positive correlation between energy efficiency and the economic fortunes of Tema Oil Refinery. This significant and positive relationship showed that energy efficiency is necessary for economic fortunes. Tema oil refinery, therefore, stands to benefit economically when the staff can ensure efficient transmission and or supply of energy. The supply of energy should have equivalence to the public consumption of energy. The results support [31] Alleyne (2018) that established a relationship between energy efficiency and profitability or benefits to oil-producing companies. The study results differ from [32] that established the fact that higher energy efficiency is often associated with higher productivity, as energy and production technologies are often linked. The study further established a converse output with [33] that investigated the prospects of energy efficiency and found that Investments in energy efficiency entail uncertainty, though it proffers higher benefits.

\subsection{The Conceptual Framework for Improving Energy Efficiency of Tema Oil Refinery (TOR)}

The study provides detailed primary and secondary data analysis to confirm the need to have in place, a common framework for improving the energy efficiency of Tema Oil Refinery through the adoption of the strategy of marching equivalence. This conceptual strategy ensures that both the left and right-hand sides of a model are roughly equivalent to project some efficiency in a model. This study suggests a working model for Tema Oil Refinery to ensure that the amount of energy supplied (in kilotonnes) is largely equivalent to the consumption of 
energy. As a caveat, the conceptual framework proposes that the energy produced and supplied should be $10 \%$ more than the last consumption of energy, as a means of catering for any contingencies. This supports the assertion of [22] that suggested a similar working model for ensuring efficiency at the workplace. [22] investigated Energy Efficiency Modelling and Estimation in Petroleum Refining Industry-A Comparison Using Physical Data that analyzed the use of the non-parametric data development analysis approach with physical data. The proposed model for the evaluation of energy efficiency does not require energy data in the operational levels for considering the structural effects. The output of the study is also supported by [23] that studied Energy Efficiency Improvement in the Petroleum Refining Industry in the United States and found that the best way of improving energy is reducing consumption. Also, [10] indicated that energy efficiency can be enhanced through the application of new technology that yields a lower input/output ratio, using the same fuel or an alternative model.

\section{Conclusions}

The study concludes that there is a linear trend between energy production (supply) and energy consumption. Massive supply of energy has resulted in an increase in energy consumption for the energy sector. This development suggests that attempts to improve energy supply would be productive because consumption is most likely to rise with increased energy production. However, the amount of energy generated in the entire economy of Ghana far exceeds the amount of energy consumed raising issues of waste or excesses that call for better policies and management plans to improve EE.

Issues of lost energy are critical to the operations of the petroleum industry and the situation is compounded by the inability to explore better ways to reduce and manage the waste. This is worsened by the fact that energy lost from plants is difficult to recover. However, managers in the petroleum industries such as TOR could improve EE by capitalizing on the staff awareness of techniques used in recovery levels at the refinery and that periodic audits are needed to help recover energy levels. This would ensure that energy recovered in time is reused in other parts of the refinery. More so, energy production activities should be guided by good policy guidelines as well as strategic management decisions so that excess production of energy is discouraged in order to reduce cost and. therefore, waste of energy resources.

The study concludes that a significant and positive correlation between energy efficiency and the economic fortunes of Tema Oil Refinery and necessary for economic fortunes. The supply of energy should have equivalence to the public consumption of energy.

An adoption of marching equivalence could be a key conceptual framework for improving EE in refineries such as Tema Oil Refinery (TOR). This conceptual strategy ensures that both the left and the right-hand sides of a model are roughly equivalent to project some level of efficiency in the model. This study 
suggests a working model for Tema Oil Refinery to ensure that the amount of energy supplied (in kilotonnes) is brought to par with the consumption of energy.

\section{Conflicts of Interest}

The authors declare no conflicts of interest regarding the publication of this paper.

\section{References}

[1] Lewin, G. (2003) Managing the Downstream Oil Supply Chain: A Customer-Led Strategy. World Energy, 10, 22-25.

[2] Gu, X., Turlapati, L., Dang, B., Tsang, C.K., Andry, P.S., Dickson, T.O., et al. (2011) High-Density Silicon Carrier Transmission Line Design for Chip-to-Chip Interconnects. 2011 IEEE 20 th Conference on Electrical Performance of Electronic Packaging and Systems, San Jose, 23-26 October 2011, 27-30.

https://doi.org/10.1109/EPEPS.2011.6100177

[3] International Energy Agency (IEA) (2016) Security of Supply in Electricity Markets: Evidence and Policy Issues. Vol. 12, International Energy Agency, Paris, 20-29.

[4] Phylipsen, G.J.M. (2010) Energy Efficiency Indicators: Best Practice and Potential Use in Developing Country Policymaking. Phylipsen Climate Change Consulting, Utrecht.

[5] IEA (International Energy Agency) (2018) $\mathrm{CO}_{2}$ Emissions from Fossil Fuel Combustion 2018. International Energy Agency.

[6] Karekezi, S. and Kithyoma, W. (Eds.) (2005) Sustainable Energy in Africa: Cogeneration and Geothermal in the East and Horn of Africa?-Status and Prospects, AFREPREN/FWD and Heinrich Boll Foundation (HBF), Nairobi.

[7] Jyoti, K. (2019) Green HRM-People Management Commitment to Environmental Sustainability. Proceedings of 10 th International Conference on Digital Strategies for Organizational Success, Gwalior, India, 5-7 January 2019, 1332-1346. https://doi.org/10.2139/ssrn.3323800

[8] Beering, S.C. (Ed.) (2011) Building a Sustainable Energy Future: US Actions for an Effective Energy Economy Transformation. DIANE Publishing, Collingdale.

[9] Ghana Energy Commission (2017) National Energy Statistics 2007-2016. Strategic Energy Planning and Policy for Ghana (2017). Ghana Energy Commission, Accra, $1-29$. https://www.energycom.gov.gh/files/ENEERGY_STATISTICS_2017_Revised.pdf

[10] Ghana Energy Commission (GEC) (2017) Energy (Supply and Demand) Outlook for Ghana. Final Report. Vol. 12, Ghana Energy Commission, Accra, 33-56.

[11] Ampofo, K. (2008) Material Selection and Embodied Energy in Ghana. Journal of Council of Scientific and Industrial Research, 31, 23-30.

[12] Arthur, J.L. and Fianu, J. (2019) Drivers of Energy Efficiency Development in Lighting and Air-Conditioning Systems in Manufacturing Industries in Ghana for 2018. Journal of Geography and Regional Planning, 12, 34-42. https://doi.org/10.5897/JGRP2019.0732

[13] Arthur, J.L. (2020) Energy Efficiency Awareness in Lighting-The Perspective of Ghana's Manufacturing Industries. African Geographical Review, 10, 33-48. https://doi.org/10.1080/19376812.2020.1755703 
[14] Balasubramanian, K. (2010) An Assessment of Downstream Petroleum Supply Chain Effectiveness: A Case of Petroleum Products Supply and Distribution in Nigeria. Salford Business School Journals, 52, 12-35.

[15] GNPC (Ghana National Petroleum Corporation) (2011) Media Statement on Government and GNPC Crude Oil Entitlements and Lifting and Marketing Arrangements in Respect of Ghana's Jubilee Field. Ghana National Petroleum Corporation, Accra.

[16] Azadeh, A., Babazadeh, R. and Asadzadeh, S.M. (2013) Optimum Estimation and Forecasting of Renewable Energy Consumption by Artificial Neural Networks. Renewable and Sustainable Energy Reviews, 27, 605-612.

https://doi.org/10.1016/j.rser.2013.07.007

[17] Ghana Exploration and Production Forum (2013). https://www.energycom.gov.gh/files/ENEERGY_STATISTICS_2017_Revised.pdf

[18] Ulusoy, Ö.F. and Pektaş, E. (2019) Recent Trends and Issues in Energy Conservation Technologies. Heritage and Sustainable Development, 1, 33-40. https://doi.org/10.37868/hsd.v1i1.9

[19] Abudu, H. and Sai, R. (2020) Examining Prospects and Challenges of Ghana's Petroleum Industry: A Systematic Review. Energy Reports, 6, 841-858.

https://doi.org/10.1016/j.egyr.2020.04.009

[20] Osabutey, D., Obro-Adibo, G., Agbodohu, W. and Kumi, P. (2013) Analysis of Risk Management Practices in the Oil and Gas Industry in Ghana. Case Study of Tema Oil Refinery (TOR). European Journal of Business and Management, 5, 139-149.

[21] Gyamfi, S., Diawuo, F.A., Kumi, E.N., Sika, F. and Modjinou, M. (2018) The Energy Efficiency Situation in Ghana. Renewable and Sustainable Energy Reviews, 82, 1415-1423. https://doi.org/10.1016/j.rser.2017.05.007

[22] Azadeh, A., Ghaderi, S.F. and Asadzadeh, S.M. (2008) Energy Efficiency Modelling and Estimation in Petroleum Refining Industry-A Comparison Using Physical Data. RE\&PQJ, 1, 123-128. https://doi.org/10.24084/repqj06.242

[23] Worrell, E. and Galitsky, C. (2005) Energy Efficiency Improvement in the Petroleum Refining Industry. 2005 ACEEE Summer Study on Energy Efficiency in Industry, NY, August 2005, 158-169.

[24] Kothari, C.R. (2004) Sample Size Determination. Research Methodology. New Age International Publications, Vol. 1, 74-81.

[25] Huberman, A.M. and Miles, M.B. (1994) Data Management and Analysis Methods.

[26] Nasiurma, D.K. (2000) Survey Sampling: Theory and Methods. University of Nairobi, Nairobi, Kenya.

[27] de Coninck, H., Revi, A., Babiker, M., Bertoldi, P., Buckeridge, M., Cartwright, A., et al. (2018) Chapter 4: Strengthening and Implementing the Global Response. In: Global Warming of $1.5 \mathrm{oC}$, IPCC-The Intergovernmental Panel on Climate Change, 313-443.

[28] Nunnally, J.C. (1978) Pyschometric Theory. 2nd Edition, McGraw-Hill, New York.

[29] Sissine, F.J. (2006) DOE Budget Earmarks: A Selective Look at Energy Efficiency and Renewable Energy R \& D Programs. Congressional Research Service, The Library of Congress.

[30] Dehghan, A.A. and Barzegar, A. (2011) Thermal Performance Behavior of a Domestic Hot Water Solar Storage Tank during Consumption Operation. Energy Conversion and Management, 52, 468-476.

https://doi.org/10.1016/j.enconman.2010.06.075 
[31] Alleyne, A. (2018) Power Density as the Key Enabler for Electrified Mobility. Polytechnica, 1, 10-18. https://doi.org/10.1007/s41050-018-0002-4

[32] Praetorius, B. and Bleyl, J.W. (2006) Improving the Institutional Structures for Disseminating Energy Efficiency in Emerging Nations: A Case Study for Energy Agencies in South Africa. Energy Policy, 34, 1520-1531.

https://doi.org/10.1016/j.enpol.2004.11.012

[33] Heutel, G. (2019) Prospect Theory and Energy Efficiency. Journal of Environmental Economics and Management, 96, 236-254.

https://doi.org/10.1016/j.jeem.2019.06.005 